\title{
Polyphenolic composition and Antioxidant Effect of Aerial Parts and Roots Extracts from Scorzonera veratrifolia
}

\author{
Duygu Taskin (D) 1, ${ }^{*}$, Mert Gecim (D)2, Ahmet Dogan (D)3, Ayfer Beceren (D)4 \\ ${ }^{1}$ Department of Analytical Chemistry, Faculty of Pharmacy, University of Health Sciences, Istanbul, Turkey \\ ${ }^{2}$ Department of Biochemistry, Faculty of Pharmacy, Marmara University, Istanbul, Turkey \\ ${ }^{3}$ Department of Pharmaceutical Botany, Faculty of Pharmacy, Marmara University, Istanbul, Turkey \\ ${ }^{4}$ Department of Pharmaceutical Toxicology, Faculty of Pharmacy, Marmara University, Istanbul, Turkey
}

\begin{abstract}
Antioxidant activities of the different extracts ( $n$-heptane, chloroform, methanol) from the roots and aerial parts of Scorzonera veratrifolia by maceration method, as well as total phenolic and flavonoid content were examined first time in this study. The findings revealed that the methanol extract from $S$. veratrifolia aerial parts exhibited greater $\mathrm{DPPH}$ radical scavenging $\left(\mathrm{IC}_{50}\right.$ : $0.62 \pm 0.60 \mathrm{mg} / \mathrm{mL}$ ) and iron (III) reduction capacity $\left(1.56 \pm 0.03 \mathrm{mM} \mathrm{Fe} \mathrm{Fe}^{2+} / \mathrm{mg}\right.$ extract). Furthermore, aerial parts methanol extract has the highest concentration of total phenolic $(46.3 \pm 1.1 \mathrm{mgGAE} / \mathrm{g}$ extract $)$ and flavonoid $(0.013 \pm 0.002 \mathrm{mg}$ $\mathrm{QE} / \mathrm{mg}$ extract) compounds. Based on these findings, the main phenolic content of aerial parts methanol extract was analyzed by LC-ESI-QTOF/MS, as this extract was found to contain the strongest antioxidant as well as the highest amount of phenolics and flavonoids as compared to the others. Quinic acid, chlorogenic acid, rutin, liquiritin, quercetin hexoside, luteolin-7-O-rutinoside, and di-O-caffeoylquinic acid compounds were identified as major compounds in methanol extract. The findings showed that aerial parts of $S$. veratrifolia, rather than its roots, could be used as a source of antioxidants.
\end{abstract}

\section{ARTICLE HISTORY}

Received: May 29, 2021

Revised: July 13, 2021

Accepted: Aug. 16, 2021

\section{KEYWORDS}

Antioxidant,

LC-MS,

Scorzonera,

Phenolic

\section{INTRODUCTION}

The accumulation of reactive species formed under oxidative stress conditions defined as the disruption of antioxidant and pro-oxidant balance in the organism causes irreparable damage to biological macromolecules in living cells. As a result, oxidative stress causes various diseases such as cancer, coronary heart disease, diabetes, hypertension, cellular deterioration, mutations, and immune system disorders (Chedea et al., 2010). Internal enzymatic defenses against oxidative damage are not entirely effective, and a series of internal and external free radicalscavenging antioxidants act as the second defense system. Antioxidants are compounds that prevent or delay the oxidation of that compound at a lower concentration than that of the oxidizable compound (Akyüz et al., 2013). Antioxidants are either a group of enzymes that

\footnotetext{
*CONTACT: Duygu Taskin $\bigotimes$ duygu.taskin@sbu.edu.tr $\equiv$ University of Health Sciences, Istanbul, Turkey, Department of Analytical Chemistry, Faculty of Pharmacy, Selimiye Mah. Tıbbiye Cad. No:38 34668 Üsküdar, İstanbul
} 
strengthen the antioxidant capacity of the cell, or molecules that inactivate free radicals or prevent chemical reactions initiated by free radicals by participating in physiological, biochemical, or cellular processes (Halliwell, 2008; Papetti et al., 2006). Phenolic compounds are secondary metabolites found in large amounts in plants. The antioxidant effects of herbal products are due to the phenolic compounds in their ingredients (Turumtay et al., 2014). Phenolic compounds exert antioxidant effects by destroying free radicals and chelating with metal ions that can form lipid peroxidation (Huyut et al., 2017).

Scorzonera species (Asteraceae) are found in traditional medicine as analgesic, antirheumatic, anthelmintic, automatic, diuretic and wound-healing, hypertension, pulmonary edema, kidney disorders, diabetes, and diarrhea (Ac1kara et al., 2013; Sar1 et al., 2009). Scorzonera species have been found to contain dihydroisocoumarin, bibenzyl derivatives, flavonoids, lignans, stilbene derivatives, quinic and caffeic acid derivatives, sesquiterpene, sesquiterpene lactones and triterpene compounds (Sar1, 2010). It has been determined by literature search that Scorzonera species show antioxidant, analgesic, anti-inflammatory, and wound-healing activities (Tsevegsuren et al., 2007; Wang et al., 2009). Scorzonera veratrifolia Fenzl plant is a perennial herbaceous plant. This plant spreads in Eastern Anatolia and grows on dry rocky slopes. The roots and latex of this plant are used as wound healing. Benzylfithalide, scorzoveratrin, scovoveratroside, chlorogenic acid, chlorogenic acid methyl ester, cryptochlorogenic acid, 4,5-dicaffeoylquinic acid and 3,5-dicaffeoylquinic acid were isolated from only the root of Scorzonera veratrifolia, and their antimicrobial activity was examined (Sar1 et al., 2009; Sar1, 2010).

No studies on the antioxidant activity of Scorzonera veratrifolia (S. veratrifolia) and the analysis of phenolic compounds have been found in the literature searches. The first aim of this study was to examine the antioxidant activities of $n$-heptane, chloroform and methanol extracts obtained from aerial parts and roots of this plant. The last aim of our study is to analyze the phenolic contents of the methanol extract from the above-ground parts of the plant, which shows the strongest activity with LC-MS/MS system.

\section{MATERIAL and METHODS}

\subsection{Identification and Collection of Plant Samples}

The aerial parts and roots of $S$. veratrifolia were collected from Tunceli in Turkey by Dr. Ahmet Dogan. The taxonomic description of the plant samples was made by Dr. Ahmet Dogan from Marmara University, Pharmacy Faculty (MARE:13917).

\subsection{Preparation of Different Extracts and Extract Yield}

The plant samples were dried at room temperature. Using the maceration procedure with $n$ heptane $(4 \times 1000 \mathrm{~mL})$, chloroform $(3 \times 700 \mathrm{~mL})$ and methanol $(4 \times 1000 \mathrm{~mL})$ solvents, extracts were produced from the aerial parts of the plant $(200 \mathrm{~g})$. Also, extracts were obtained from the roots of the plant $(50 \mathrm{~g})$ using $n$-heptane $(4 \times 300 \mathrm{~mL})$, chloroform $(3 \times 400 \mathrm{~mL})$ and methanol $(4 \times 500 \mathrm{~mL})$ solvents, respectively. The solvents were then filtered via filter paper and evaporated under low pressure in a rotary evaporator, with the raw extracts preserved in the refrigerator. Table 1 shows the yield percentages and extract quantities of the various extracts from the plant. The aerial components of the methanol extract $(10.12 \mathrm{~g})$ were found to be more abundant than the other extracts. Furthermore, when the yield percentages of the extracts were compared, it was discovered that the methanol extract (11.96\%) made from the plant roots had the highest yield percentage. 
Table 1. Amount and percentage yield (\%) of S. veratrifolia in different extracts.

\begin{tabular}{lcc}
\hline Extracts & $\begin{array}{c}\text { Amount } \\
(\mathrm{g})\end{array}$ & $\begin{array}{c}\text { Yield } \\
(\%)\end{array}$ \\
\hline Aerial parts $n$-heptane & 7.55 & 3.78 \\
Aerial parts chloroform & 3.64 & 1.82 \\
Aerial parts methanol & 10.12 & 5.06 \\
Root methanol & 5.98 & 11.96 \\
Root chloroform & 2.45 & 2.05 \\
Root heptane & 1.12 & 1.02 \\
\hline
\end{tabular}

\subsection{Determination of Total Amount of Phenolic Substances}

Distilled water was added to the extracts prepared at concentrations of $1-5 \mathrm{mg} / \mathrm{mL}$ and taken into tubes of $0.1 \mathrm{~mL}$ each, and their volume was $4.6 \mathrm{~mL} .0 .1 \mathrm{ml}$ Folin-Ciocalteu reagent and $0.3 \mathrm{~mL}$ of $2 \%$ sodium carbonate solution added to the absorbance of the color that occurs after being kept in a shaking water bath for 2 hours under room conditions. It was measured at 760 $\mathrm{nm}$ in comparison to a standard (Samatha et al., 2012).

Preparation of the calibration curve of gallic acid: total phenolic substance was determined by using Folin-Ciocalteu reagent to the gallic acid solutions prepared at concentrations of 0.05 $0.40 \mathrm{mg} / \mathrm{mL}$. The calibration curve was prepared by plotting the concentrations against the measured absorbances and the correct equation was obtained [(Abs=75.63 [GA]x-0.044 $\left(\mathrm{R}^{2}=\right.$ $0.9963)]$. From the obtained equation, the total phenolic amounts of the samples were calculated as the equivalent of $\mathrm{mg}$ gallic acid (mg GAE/g extract).

\subsection{Determination of the Total Amount of Flavonoid Substances}

Total flavonoid amounts of plant extracts were determined by aluminum chloride color measurement method equivalent to quercetin (Samatha et al., 2012). Briefly, 0.5 mL of each of the different extracts was taken and mixed with distilled water of $2 \mathrm{~mL}$. Then, $0.15 \mathrm{~mL}$ of $5.0 \%(\mathrm{w} / \mathrm{v}) \mathrm{NaNO}_{2}$ solution was added, and this mixture was left for 6 minutes. Then, $0.15 \mathrm{~mL}$ of $10 \% \mathrm{AlCl}_{3}$ solution was added to the mixture, and after 6 minutes of incubation, $2 \mathrm{~mL}$ of $4.0 \%(\mathrm{w} / \mathrm{v}) \mathrm{NaOH}$ solution was added to the mixture. Finally, the total volume of the mixture was completed with $5 \mathrm{~mL}$ of distilled water, and the absorbance values against the reference solution were measured at $510 \mathrm{~nm}$, in which the pink colored flavonoid-aluminum complex in the alkaline medium gave maximum absorbance after 15 minutes.

\subsection{DPPH (2,2-diphenyl-1-picrylhydrazyl) Radical Scavenging Activity}

The 2,2-diphenyl-1-picrylhydrazyl (DPPH) radical was used to test the extracts' free radical scavenging activity (Wei et al., 2010). $3.9 \mathrm{~mL}$ of $0.1 \mathrm{mM} \mathrm{DPPH}$ solution was added to $0.1 \mathrm{~mL}$ of extracts prepared at known concentration and standard solution (ascorbic acid). After mixing the mixture with vortex, it was left at room temperature and in the dark for 30 minutes. UV-vis spectroscopy was used to determine the activity of the extracts, with at least three duplicate measurements taken at $517 \mathrm{~nm}$. The control was prepared under the same conditions using 0.1 $\mathrm{mL}$ methanol instead of sample and standard substance. The absorbance of the control was measured daily. Before the $\mathrm{IC}_{50}$ value was calculated, the \% DPPH radical scavenging activity was calculated with the formula given below:

$\mathrm{DPPH}$ radical removal capacity $\left.=\left[\left(\mathrm{A}_{0}-\mathrm{A}_{1}\right) / \mathrm{A}_{0}\right] \times 100\right]$

$\mathrm{A}_{0}$ : Absorbance of the control solution,

$\mathrm{A}_{1}$ : Plant extracts and absorbance of standard solutions

$\mathrm{IC}_{50}$ is the concentration of extract or standard material that causes a $50 \%$ reduction in initial DPPH concentration. This value was calculated using the correct equation obtained by placing 
the $\%$ free radical removal activity values against the studied concentrations and the results were given as $\mathrm{IC}_{50}=\mathrm{mg} / \mathrm{mL}$.

\subsection{Iron (III) Reduction/Antioxidant Power (FRAP) Method}

Acetate buffer (pH 3.6) $25 \mathrm{~mL}$ of $300 \mathrm{mM}, 2.5 \mathrm{~mL}$ of TPTZ solution (solution of $10 \mathrm{mM} \mathrm{TPTZ}$ in $40 \mathrm{mM} \mathrm{HCl}$ ), and $2.5 \mathrm{~mL}$ of $20 \mathrm{mM} \mathrm{FeCI} 3.6 \mathrm{H}_{2} \mathrm{O}$ were mixed and kept at $37{ }^{\circ} \mathrm{C}$ for 30 minutes. In the fourth minute, an increase in absorbance was detected at $593 \mathrm{~nm}$. against the reference prepared by mixing $3.8 \mathrm{~mL}$ of the FRAP reagent with $0.2 \mathrm{~mL}$ of extract and by adding distilled water instead of the extract. The absorbance values of the extracts at $593 \mathrm{~nm}$ were compared with the values of the calibration plot $\left[\mathrm{Abs}=0.8226\left[\mathrm{FeSO}_{4}\right] \mathrm{x}-0.0338\left(\mathrm{R}^{2}=0.9940\right)\right]$ prepared with $\mathrm{FeSO}_{4} .7 \mathrm{H}_{2} \mathrm{O}$, and the FRAP value was expressed as $\mathrm{mM} \mathrm{FeSO} / \mathrm{mg}$ extract (Benzie \& Strain, 1996).

\subsection{LC-ESI-QTOF/MS Analysis}

The phenolic compounds of methanol extract from aerial parts of plant were determined by LCESI-QTOF/MS technique. An Agilent 6530 was used for the separation and analysis of phytochemicals. The chromatographic separation was performed on reverse phase Agilent Poroshell C18 (3.0 x $150 \mathrm{~mm}, 2.7 \mu \mathrm{m})$ analytical column. The column temperature was set to $30{ }^{\circ} \mathrm{C}$. The separation was carried with a gradient binary mixture of solvent $\mathrm{A}(0.1 \%$ aqueous formic acid) and solvent $\mathrm{B}$ (acetonitrile) at a flow rate of $0.4 \mathrm{~mL} / \mathrm{min}: 0-2 \mathrm{~min} \mathrm{10 \%} \mathrm{B;} 2-6 \mathrm{~min}$ $10-50 \% \mathrm{~B}$; $6-8 \min 50 \% \mathrm{~B}$; 8-12 $\min 10-90 \% \mathrm{~B}$; $12-14 \min 10-90 \% \mathrm{~B}$; $14-14.01 \min 90-10 \% \mathrm{~B}$ and stop time is $20.00 \mathrm{~min}$. The electrospray ionization mass spectrometer (ESI/MSn) in negative ion mode was used to create the MS spectra of the most abundant ion. Helium was employed as the collision gas. Nitrogen was employed as a nebulizing gas, a 10-arbitrary-unit auxiliary gas flow, and a 35-arbitrary-unit sheath gas flow. The spray voltage was set to 5.00 $\mathrm{kV}$, while the capillary temperature and voltage were set to 300 degrees Celsius and 35.00 volts, respectively. $10 \mathrm{mg}$ of the extract was dissolved in $3 \mathrm{~mL}$ of methanol-water solution $(2: 1 \mathrm{v} / \mathrm{v})$. The filtrate was then filtered into the vial to $1.5 \mathrm{~mL}$ using a filter and syringe and $10 \mu \mathrm{L}$ sample was injected to LC.

\subsection{Statistical Analysis}

All the results were performed in triplicate and illustrated in terms of mean $\pm \mathrm{SD}$. One-way analysis of variance was performed following ANOVA procedures, and significant differences between means were determined by Tukey Multiple Comparison test. $p<0.05$ was considered statistically significant.

\section{RESULTS / FINDINGS}

\subsection{Determination of Total Flavonoid and Phenolic Content}

Total phenolic and flavonoid amounts of different extracts of plant were determined in this study. According to the results, $46.3 \pm 1.1$ gallic acid equivalents per gram extract was detected as the number of total phenolics of the methanol extract from plant's aerial parts. Besides, it was determined that the methanol extract $(0.013 \pm 0.020$ quercetin equivalents per milligram extract) from plants aerial parts had the highest amount of flavonoid compounds. In this study, the phenolic compounds content of the aerial parts and root extracts of the plant was compared, and it was found that all extracts from the aerial parts contained a higher amount of phenolic and flavonoid compounds than the root extracts (Table 2).

The total flavonoid and phenolic contents of the different extracts (water, ethyl acetate, chloroform, ether, $n$-butanol) of the aerial parts and roots of the $S$. paradoxa was determined. According to the results, it was determined that the $n$-butanol extracts from the aerial parts contain higher amounts of phenolic $(11.86 \pm 0.10 \mathrm{mg}$ tannic acid equivalents/g extract) and 
flavonoid (6.42 $\pm 0.04 \mathrm{mg}$ rutin equivalents $/ \mathrm{g}$ extract) compounds than the other extracts (Nasseri et al., 2015). In our study, it was observed that methanol extract of $S$. veratrifolia aerial parts contains higher amounts of phenolic (46.3 \pm 1.1 gallic acid equivalents per gram extract) and flavonoid $(0.013 \pm 0.020$ quercetin equivalents per milligram extract) compounds than other extracts.

Table 2. Total phenolic and flavonoid contents of different extracts from various parts of S. veratrifolia.

\begin{tabular}{lcc}
\hline Extracts & $\begin{array}{c}\text { Total phenolic } \\
(\mathrm{mgGAE} / \mathrm{g} \text { extract })\end{array}$ & $\begin{array}{c}\text { Total flavonoid }(\mathrm{mg} \\
\text { QE/mg extract) }\end{array}$ \\
\hline Aerial parts methanol & $46.3 \pm 1.1^{\mathrm{a}}$ & $0.013 \pm 0.002^{\mathrm{a}}$ \\
Aerial parts chloroform & $16.5 \pm 1.5^{\mathrm{b}}$ & $0.0055 \pm 0.011^{\mathrm{b}}$ \\
Aerial parts $n$-heptane & $8.1 \pm 2.3^{\mathrm{c}}$ & $0.002 \pm 0.003^{\mathrm{c}}$ \\
Root methanol & $10.0 \pm 1.6^{\mathrm{d}}$ & $0.004 \pm 0.011^{\mathrm{d}}$ \\
Root chloroform & $4.1 \pm 2.5^{\mathrm{e}}$ & $0.001 \pm 0.025^{\mathrm{e}}$ \\
Root $n$-heptane & $1.2 \pm 1.9^{\mathrm{f}}$ & $0.001 \pm 0.032^{\mathrm{f}}$ \\
\hline
\end{tabular}

The mean of three independent determinations $(n=3)$ is used to calculate the standard deviation. GAE-Gallic acid equivalents; QE-Quercetin equivalents. a-f Means in a row without a common superscript letter differ $(p<0.05)$, as analyzed by one-way ANOVA.

\subsection{Scavenging Activity of DPPH Radical Assay}

The DPPH test is a widely used spectrophotometric method to determine the antioxidant capacity of plants or foods (Bursal et al., 2020). The $\mathrm{IC}_{50}$ values of the extracts and standards for DPPH radical scavenging were found as; ascorbic acid $(0.004 \pm 0.003)>$ aerial parts methanol $(0.62 \pm 0.60)>$ roots chloroform $(1.14 \pm 0.01)>$ roots heptane $(1.37 \pm 0.21)>$ roots methanol $(2.76 \pm 0.28)>$ aerial parts chloroform $(2.82 \pm 0.04)>$ aerial parts $n$-heptane (4.15 \pm 0.02$)$. According to the findings, the methanol extract of aerial parts had much higher DPPH radical scavenging activity than the other extracts. (Table 3 ).

\subsection{Ferric Ions $\left(\mathrm{Fe}^{3+}\right)$ Reduction Abilities of Different Extracts}

The reduction potentials of different extracts obtained from the plants aerial parts and roots were determined by reduction systems including FRAP capability. $\mathrm{Fe}^{3+}$ reducing powers of the extracts and standards were decreased as; BHT (1.2 \pm 0.21$)>$ aerial parts methanol $(1.56 \pm 0.03)>$ roots methanol $(1.02 \pm 0.05)>$ aerial parts chloroform $(0.980 \pm 0.002)>$ roots chloroform $(0.97 \pm 0.47)>$ roots $n$-heptane $(0.82 \pm 0.51)>$ aerial parts $n$-heptane $(0.22 \pm 0.06)$. In this study, it was found that methanol extracts from the aerial parts and roots of the plant had potent iron reduction capacity from other extracts, while they had a lower capacity than the standard compound (Table 3).

Table 3. Free radical scavenging activity and FRAP of different extracts from various parts of $S$. veratrifolia.

\begin{tabular}{lll}
\hline Extracts/standards & $\mathrm{DPPH} \cdot\left(\mathrm{IC}_{50}: \mathrm{mg} / \mathrm{mL}\right)$ & FRAP assay $\left(\mathrm{mM} \mathrm{Fe}^{2+} / \mathrm{mg} \mathrm{extract}^{\mathrm{a}}\right)$ \\
\hline Aerial parts methanol & $0.62 \pm 0.60^{\mathrm{a}}$ & $1.56 \pm 0.03^{\mathrm{a}}$ \\
Aerial parts chloroform & $2.82 \pm 0.04^{\mathrm{b}}$ & $0.98 \pm 0.002^{\mathrm{b}}$ \\
Aerial parts $n$-heptane & $4.15 \pm 0.02^{\mathrm{c}}$ & $0.22 \pm 0.06^{\mathrm{c}}$ \\
Root methanol & $2.76 \pm 0.28^{\mathrm{d}}$ & $1.02 \pm 0.05^{\mathrm{d}}$ \\
Root chloroform & $1.14 \pm 0.01^{\mathrm{e}}$ & $0.97 \pm 0.47^{\mathrm{e}}$ \\
Root $n$-heptane & $1.37 \pm 0.21^{\mathrm{f}}$ & $0.82 \pm 0.51^{\mathrm{f}}$ \\
Ascorbic acid & $0.004 \pm 0.003^{\mathrm{g}}$ & \\
BHT & & $1.2 \pm 0.21^{\mathrm{g}}$ \\
\hline
\end{tabular}

Values are mean of triplicate determination $(\mathrm{n}=3) \pm$ standard deviation; a-g Means in a row without a common superscript letter differ $(p<0.05)$, as analyzed by one-way ANOVA. 


\subsection{Identification of phytochemical compounds by LC-ESI-QTOF/MS}

In the present study, the antioxidant activities of the extracts obtained from different parts of the plant using different solvents, as well as the total phenolic and flavonoid substance amounts were compared among themselves. The methanol extract from the plants aerial parts was shown to have the highest antioxidant activity as well as total phenolic and flavonoid contents. In line with this result, the LC-QTOF/MS device was used to qualitatively analyze the main phenolic molecules in methanol extract that might be responsible for the activity (Figure 1). The presence of quinic acid, chlorogenic acid, rutin, liquiritin, quercetin hexoside, luteolin-7-O-rutinoside and di-O-caffeoylquinic acid (Table 4) in the methanol extract from aerial parts was determined in this investigation.

Figure 1. MS base peak chromatogram (BPC) of methanol extract from S. veratrifolia.

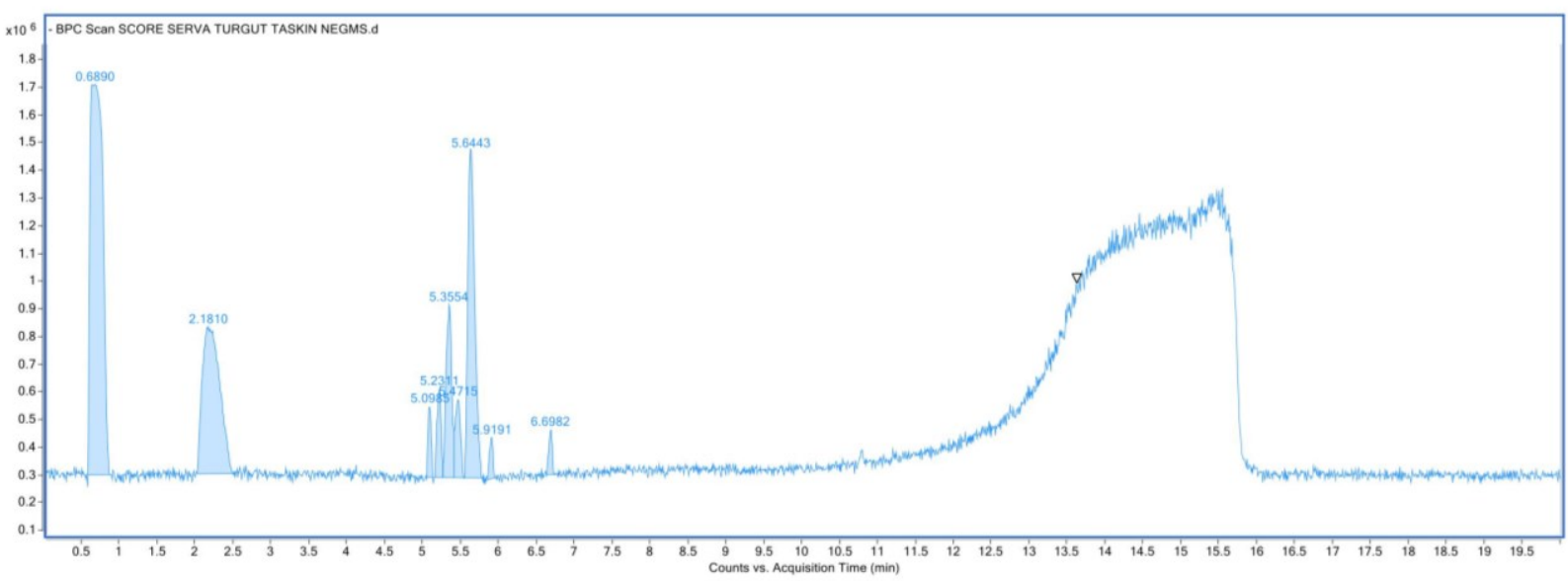

Table 4. Identification of polyphenols in S. veratrifolia by LC-ESI-TANDEM MS data

\begin{tabular}{|c|c|c|c|c|}
\hline$\overline{\mathrm{Rt} \text { (Min) }}$ & {$[\mathrm{M}-\mathrm{H}]^{-}$} & Other MS-MS ions (M/Z) & Identification & Reference \\
\hline 0.7173 & 191.0569 & $171,155,127,93,85$ & quinic acid & $*$ \\
\hline 2.0564 & 353.0907 & 191 & chlorogenic acid & $*$ \\
\hline 2.1073 & 707.1843 & 353,191 & chlorogenic acid dimer & $*$ \\
\hline 5.0809 & 609.1528 & $300,271,151$ & rutin & $*$ \\
\hline 5.2578 & 417.1193 & 255,169 & liquiritin & (Simirgiotis et al., 2015). \\
\hline 5.2829 & 463.0923 & $300,271,151,112,69$ & quercetin hexoside & Hofmann et al., 2016 \\
\hline 5.3589 & 593.1568 & $285,255,151$ & luteolin-7- $O$-rutinoside & Simirgiotis et al., 2015 \\
\hline 5.4431 & 515.1266 & $353,179,135$ & $\begin{array}{l}\text { di- } O \text {-caffeoylquinic } \\
\text { acid }\end{array}$ & Schütz et al., 2005 \\
\hline
\end{tabular}

*Compounds identified by comparing retention times and MS data with those of reference

As shown in Supporting Information, quinic acid gave a molecular ion at $\mathrm{m} / \mathrm{z} 191$. This compounds MS/MS fragmentation pattern revealed a distinct $\mathrm{m} / \mathrm{z}$ at 171,155 with water loss and then 93 fragments of mass with the loss of carbon dioxide. Chlorogenic acid produced deprotonated molecules at $\mathrm{m} / \mathrm{z}$ 353. The MS/MS fragmentation pattern obtained from chlorogenic acid revealed a characteristic $\mathrm{m} / \mathrm{z}$ at 191 and 161 by separating the caffeoyl portion and separating the quinic and one molecule of water, respectively. The precursor ion at $\mathrm{m} / \mathrm{z} 707$ was identified as chlorogenic acid dimer, and the fragment ion at $\mathrm{m} / \mathrm{z} 353$ was a fragment of chlorogenic acid ( $\mathrm{m} / \mathrm{z} 354)$ that lost a hydrogen ion fragment when mass spectrometry was used in negative mode. The fragment of quinine $(\mathrm{m} / \mathrm{z} 192)$, which lost a hydrogen ion fragment, was another ion at $\mathrm{m} / \mathrm{z} 191$. Rutin produced deprotonated molecules at $\mathrm{m} / \mathrm{z} 609$ and the sugar portion was separated and gave a fragment of quercetin aglycone at a molecular weight of $300 \mathrm{~g} / \mathrm{mol}$. The peak with retention time at 5.26 was liquiritin and gave $\mathrm{m} / \mathrm{z} \mathrm{255}$, the molar mass of the 
4',7-dihydroxyflavanon (Simirgiotis et al., 2015). At $\mathrm{m} / \mathrm{z} 463$, quercetin hexoside formed a deprotonated molecule, and a fragment of the aglycon ion peak provided a quercetin monosaccharide at $\mathrm{m} / \mathrm{z} 300.0303$ ([M-H-162] $]^{-}$loss of hexose fragments) (Hofmann et al., 2016). There is a parent ion at $\mathrm{m} / \mathrm{z} 593$ and fragment ions corresponding to the luteolin aglycon at $\mathrm{m} / \mathrm{z} 285,255$ and 151 . This compound has been proven in the relevant literature to be luteolin7-O-rutinoside. (Simirgiotis et al., 2015). The peak with retention time at 5.44 was tentatively deduced as di-O-caffeoylquinic acid (Schütz et al., 2005), which gave fragment ion at $\mathrm{m} / \mathrm{z} 353$ M-H-caffeoyl as follows; m/z 173 fragments was formed by the separation of M-H-caffeoylquinic molecule ions.

\section{DISCUSSION and CONCLUSION}

According to the literature research, there are just a few research studies on this species. It was also found that the water extract $(3.36 \pm 0.28 \mathrm{mg}$ tannic acid equivalents/g extract) from the roots contains high amounts of phenolics, while the $n$-butanol extract $(0.15 \pm 0.01 \mathrm{mg}$ rutin equivalents/g extract) contains high amounts of flavonoids (Nasseri et al., 2015). Unlike this study, the methanol extract of $S$. veratrifolia roots was found to possess greater levels of phenolic (10.00 \pm 0.01 gallic acid equivalents per gram extract) and flavonoid $(0.004 \pm 0.011$ quercetin equivalents per milligram extract) compounds than other extracts. In this study, the antioxidant potential of root and aerial parts extracts of the $S$. veratrifolia for the first time was examined in comparison with the standard.

The antioxidant capacities of Scorzonera species have been investigated in the studies. It was stated that water extract from the aerial parts of S. suberosa $\left(\mathrm{IC}_{50}: 42.33 \pm 1.60 \mathrm{mg} / \mathrm{mL}\right) \mathrm{S}$. laciniata ( $\left.\mathrm{IC}_{50}: 77.07 \pm 1.88\right)$ S. latifolia $\left(\mathrm{IC}_{50}: 29.36 \pm 1.46\right.$ ) showed median DPPH radical scavenging activity (Erden et al., 2013). In the present study, it was observed that the methanol extract $\left(\mathrm{IC}_{50}: 0.62 \pm 0.60 \mathrm{mg} / \mathrm{mL}\right.$ ) from $S$. veratrifolia aerial parts has higher DPPH radical scavenging activity than the water extract from aerial parts of $S$. suberosa, S. laciniata and $S$. latifolia. The DPPH radical scavenging potential of the methanol:water $(80: 20 \mathrm{v} / \mathrm{v})$ extract from the aerial parts and roots of the $S$. latifolia was determined. It has been determined that the aerial parts $\left(\mathrm{IC}_{50}: 1.036 \mathrm{mg} / \mathrm{mL}\right.$ ) have an effective radical scavenging effect compared to the root extract ( $\mathrm{IC}_{50}: 4.102 \mathrm{mg} / \mathrm{mL}$ ) (Açıkara et al., 2017). In the present study, the DPPH radical scavenging activity of the aerial parts and root parts of $S$. veratrifolia was examined in parallel with the literature. When the results were examined, it was discovered that methanol extracts from $S$. veratrifolia aerial parts ( $\mathrm{IC}_{50}: 0.62 \pm 0.60 \mathrm{mg} / \mathrm{mL}$ ) and roots $\left(\mathrm{IC}_{50}: 2.76 \pm 0.28 \mathrm{mg} / \mathrm{mL}\right.$ ) had higher radical scavenging activity than methanol: water $(80: 20 \mathrm{v} / \mathrm{v})$ extracts from S. latifolia aerial parts and roots.

A previous study found that the methanol extract $(10.8 \%, 50 \mu \mathrm{g} / \mathrm{mL})$ from the aerial parts of S. tomentosa L showed lower radical scavenging activity compared to ascorbic acid $(96.78 \%$, $100 \mu \mathrm{g} / \mathrm{mL}$ ) (Karagöz et al., 2015). In our present study, it was determined that all extracts of $S$. veratrifolia showed lower activity than ascorbic acid in parallel with the literature.

It was stated that the methanol extract ( $\mathrm{IC}_{50}: 18.81 \mathrm{mg} / \mathrm{mL}$ ) from the $S$. paradoxa aerial parts showed more effective DPPH radical scavenging activity than the root extract $\left(\mathrm{IC}_{50}: 88.9\right.$ $\mathrm{mg} / \mathrm{mL}$ ) (Nasseri et al., 2015). According to our findings, it was determined that the methanol extract of $S$. veratrifolia aerial parts $\left(\mathrm{IC}_{50}: 0.62 \pm 0.60 \mathrm{mg} / \mathrm{mL}\right.$ ) has more effective DPPH radical scavenging activity than the root ( $\mathrm{IC}_{50}: 2.76 \pm 0.28 \mathrm{mg} / \mathrm{mL}$ ) extract and has a stronger radical scavenging effect than the methanol extracts from $S$. paradoxa aerial parts and roots.

In the literature search, benzylfithalide, scorzoveratrin, scovoveratroside, chlorogenic acid, chlorogenic acid methyl ester, cryptochlorogenic acid, 4,5-dicaffeoylquinic acid and 3,5dicaffeoylquinic acid compounds were isolated from the root of the S. veratrifolia, but no study was found about the analysis of phenolic compounds both in the aerial parts by LC-ESI- 
QTOF/MS system (Sar1 et al., 2009; Sar1, 2010). The phenolic compounds analysed in methanol extract of aerial parts, which possesses strong antioxidant activity, were investigated for the first time in this work. It was analyzed by HPLC system that the methanol: water $(80: 20$ $\mathrm{v} / \mathrm{v}$ ) extract from aerial parts of the $S$. latifolia contained high amounts of chlorogenic acid and hyperoside compounds (Açıkara et al., 2017). In our current study, it was determined by HPLC system that the methanol extract from $S$. veratrifolia aerial parts contains chlorogenic acid like $S$. latifolia in parallel with the literature.

This study provided information about antioxidant activity and phytochemical composition of $S$. veratrifolia. The antioxidant activity of different extracts from the root and aerial parts of the plant was examined and the aerial parts methanol extract was determined to have the highest antioxidant activity. Furthermore, when compared to other extracts, the methanol extract contained the highest amount of phenolics and flavonoids. It was analyzed by LC-ESIQTOF/MS that the methanol extract from aerial parts substantially contained quinic acid, chlorogenic acid, rutin, liquiritin, quercetin hexoside, di-O-caffeoylquinic acid, and luteolin-7$O$-rutinoside compounds. These analysed compounds show antioxidant properties because they contain many hydroxyl groups attached to their aromatic rings. Hence, this extract can be used as a natural medicinal and nutritional source in the future after detailed analysis tests.

\section{Acknowledgments}

This study was funded by the Scientific and Technological Research Council of Turkey (TUBITAK) Grant No 217S050.

\section{Declaration of Conflicting Interests and Ethics}

The authors declare no conflict of interest. This research study complies with research and publishing ethics. The scientific and legal responsibility for manuscripts published in IJSM belongs to the author(s).

\section{Authorship Contribution Statement}

Authors are expected to present author contributions statement to their manuscript such as; Duygu Taskin: Investigation, Writing-original draft, Supervision. Mert Gecim: Investigation. Ahmet Dogan: Plant collection Ayfer Beceren: Supervision.

Orcid

Duygu Taskin (iD) https://orcid.org/0000-0002-5279-0900

Mert Geçim (D) https://orcid.org/0000-0002-9575-7801

Ahmet Dogan (iD) https://orcid.org/0000-0003-0603-5100

Ayfer Beceren (iD) https://orcid.org/0000-0002-6770-6089

\section{REFERENCES}

Acıkara, O.B., C1tıglu, G.S., \& Ozkan, A.M.G. (2013). Qualitative and quantitative analysis of phenolic acids in Scorzonera tomentosa L. Turk J Pharm Sci., 10, 1-8.

Acıkara, O.B., Ergene, B., Bakar, F., Citoglu, G.S., \& Nebioglu, S. (2017). Evaluation of Antioxidant Activities and Phenolic Compounds of Scorzonera latifolia (Fisch. \& Mey.) DC. Collected from Different Geographic Origins in Turkey. Turk J Pharm Sci., 14, 179184. http://dx.doi.org/10.4274/tjps.57070

Akyüz, E., Özyürek, M., Güçlü, K., \& Apak, M.R. (2013). Novel pro-oxidant activity assay for polyphenols vitamins $\mathrm{C}$ and $\mathrm{E}$ using a modified CUPRAC method. Talanta., 115, 583-589. https://doi.org/10.1016/j.talanta.2013.06.006

Benzie, I.F., \& Strain, J.J. (1996). The ferric reducing ability of plasma (FRAP) as a measure of "antioxidant power": the FRAP assay. Anal Biochem., 239, 70-76. https://doi.org/10.100 $\underline{\text { 6/abio.1996.0292 }}$ 
Bursal, E., Taslimi, P., Goren, A.C., \& Gulcin, I. (2020). Assessments of anticholinergic, antidiabetic, antioxidant activities and phenolic content of Stachys annua. Biocatal. Agric. Biotechnol., 28, 101711. https://doi.org/10.1016/j.bcab.2020.101711

Chedea, V.S., Braicu, C., \& Cocaciu, C. (2010). Antioxidant/prooxidant activity of a polyphenolic grape seed extract. Food Chemi., 121, 132-139. https://doi.org/10.1016/j.food chem.2009.12.020

Erden, Y., Kirbag, S., \& Y1lmaz, O. (2013). Phytochemical Composition and Antioxidant Activity of Some Scorzonera Species. Proc. Natl. Acad. Sci., India, Sect. B Biol. Sci., 83, 271-276. http://dx.doi.org/10.1007/s40011-012-0129-7

Halliwell, B. (2008). Are polyphenols antioxidants or pro-oxidants? What do we learn from cell culture and in vivo studies?. Arch. Biochem. Biophys., 476, 107-112. https://doi.org/10.101 6/j.abb.2008.01.028

Hofmann, T., Nebehaj, E., \& Albert, L. (2016). Antioxidant properties and detailed polyphenol profiling of Europeanhornbeam (Carpinus betulus L.) leaves by multiple antioxidantcapacity assays and high performance liquid chromatography/multistage electrospray mass spectrometry. Ind Crop Prod., 87, 340-349. https://doi.org/10.1016/j.ind crop.2016.04.037

Huyut, Z., Beydemir, Ş., \& Gülçin, İ. (2017). Antioxidant and Antiradical Properties of Selected Flavonoids and Phenolic Compounds. Biochem Res Int., 2017, 10. https://doi.org/10.1155/ $2017 / 7616791$

Karagöz, A., Artuna, F.T., Ozcan, G., Melikoglu, G., Anıl, S., Kultur, S., \& Sutlupınar, N. (2015). In vitro evaluation of antioxidant activity of some plant methanol extracts. Biotechnol Biotec EQ., 29, 1184-1189. http://dx.doi.org/10.1080/13102818.2015.1080600

Nasseri, M.A., Bigy, S.S., Allahresani, A., \& Malekaneh, M. (2015). Assessment of Antioxidant Activity, Chemical Characterization and Evaluation of Fatty Acid Compositions of Scorzonera paradoxa Fisch and C. A. Mey. Jundishapur J Nat Pharm Prod., 10, 19781. http://dx.doi.org/10.17795/jjnpp-19781

Papett1, A., Daglıa, M., Grısolı, P., Dacarro, C., Gregott1, C., \& Gazzanı, G. (2006). Anti- and pro-oxidant activity of Cichorium genus vegetables and effect of thermal treatment in biological systems. Food Chem., 97, 157-165. https://doi.org/10.1016/j.foodchem.2005.03. $\underline{036}$

Samatha, T., Shyamsundarachary, R., Srinivas, P., \& Swamy, N.R. (2012). Quantification of total phenolic and total flavonoid contents in extracts of Oroxylum indicum L. Kurz. Asian J. Pharmaceut. Clin. Res., 5, 177-179.

Sar1, A. (2010). Two new 3-benzylphthalides from Scorzonera veratrifolia Fenzl. Nat Prod Res. 24, 56-62. http://dx.doi.org/10.1080/14786410902800699

Sar1, A., Ozbek, B., \& Ozgokce, F. (2009). Antimicrobial activities of two Scorzonera species growing in Turkey. Asian J Chem. Commun., 21, 4785-4788.

Schütz, K., Kammerer, D.R., Carle, R., \& Schieber, A. (2005). Characterization of phenolic acids and flavonoids in dandelion (Taraxacum officinale WEB. ex WIGG.) root and herb by high-performance liquid chromatography/electrospray ionization mass spectrometry. Rapid Commun. Mass Spectrom.,19, 179-186. https://doi.org/10.3390/10.1002/rcm.1767

Simirgiotis, M.J., Benites, J., Areche, C., \& Sepulveda, B. (2015). Antioxidant Capacities and Analysis of Phenolic Compounds in Three Endemic Nolana Species by HPLC-PDA-ESIMS. Molec., 20, 11490-11507. https://doi.org/10.3390/molecules200611490

Tsevegsuren, N., Edrada, R., Lin, W., Ebel, R., Torre, C., Ortlepp, S., Wray, V., \& Proksch, P. (2007). Biologically active natural products from Mongolian medicinal plants Scorzonera divaricate and Scorzonera pseudodivaricata. J Nat Prod., 70, 962-967. http://dx.doi.org/10 $.1021 / \mathrm{np} 070013 \mathrm{r}$ 
Turumtay, E.A., Islamoglu, F., Cavus, D., Sahin, H., \& Turumtay, H. (2014). Bartel Vanholme Correlation between phenolic compounds and antioxidant activity of Anzer tea (Thymus praecox Opiz subsp. Caucasicus var. caucasicus). Ind Crop Prod., 52, 687-694. https://doi. org/10.1016/j.indcrop.2013.11.042

Wang, Y., Edrada-Ebel, R.A., Tsevegsuren, N., Sendker, J., Braun, M., Wray, V., Lin, W., \& Proksch, P. (2009). Dihydrostilbene Derivatives from the Mongolian Medicinal Plant Scorzonera radiata. J. Nat. Prod., 72, 671-675. http://dx.doi.org/10.1021/np800782f

Wei, F., Jinglou, C., Yaling, C., Yongfang, L., Liming, C., Lei, P., Zhou, D., Liang, X., \& Ruan, J. (2010). Antioxidant, free radical scavenging, antiinflammatory and hepatoprotective potential of the extract from Parathelypteris nipponica (Franch.et Sav.) Ching. J. Ethnopharmacol., 130, 521-528. https://doi.org/10.1016/j.jep.2010.05.039 


\section{APPENDIX}

\section{Supporting Information}

Figure S1. MS/MS spectra and fragmentation patterns of quinic acid in S. veratrifolia.

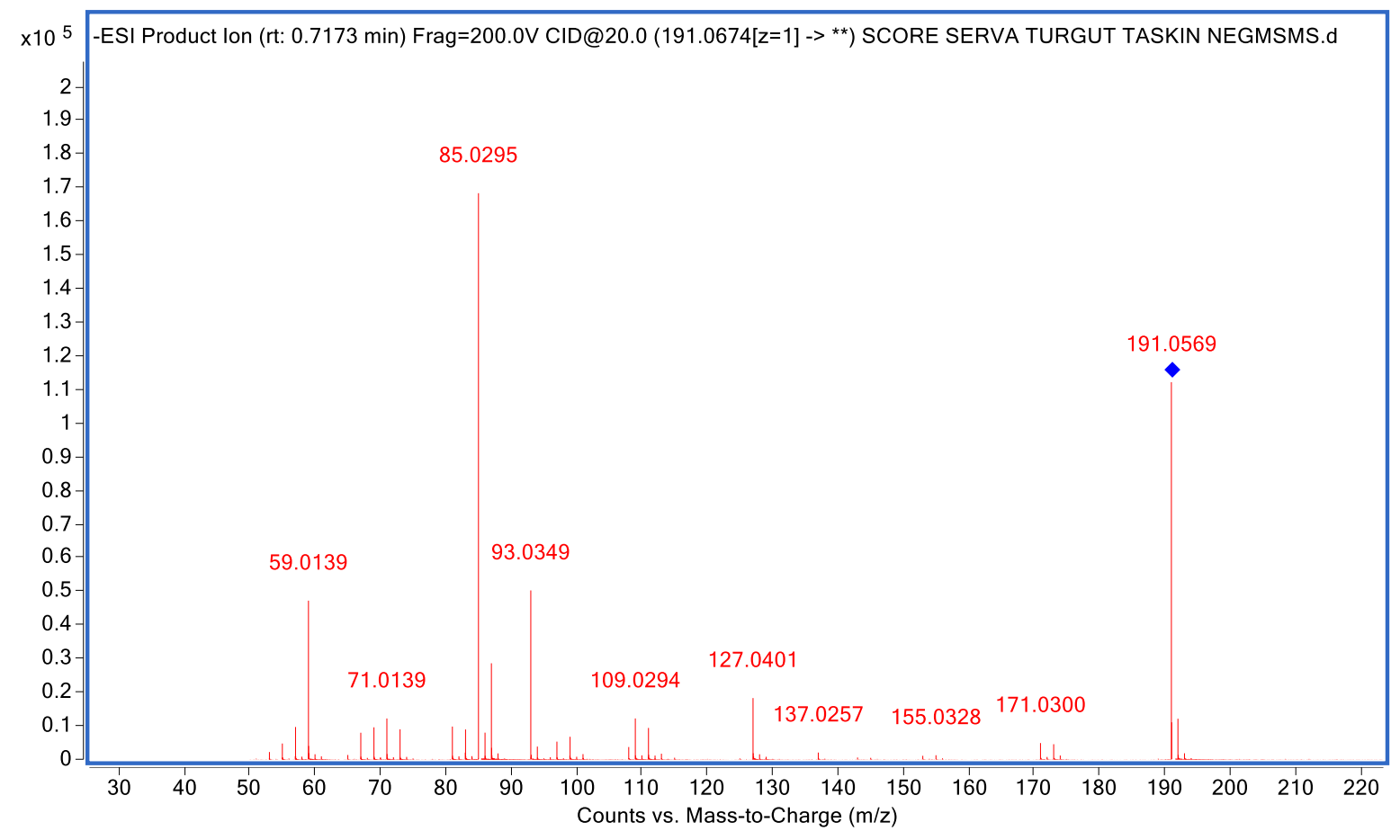

Figure S2. MS/MS spectra and fragmentation patterns of chlorogenic acid in S. veratrifolia.

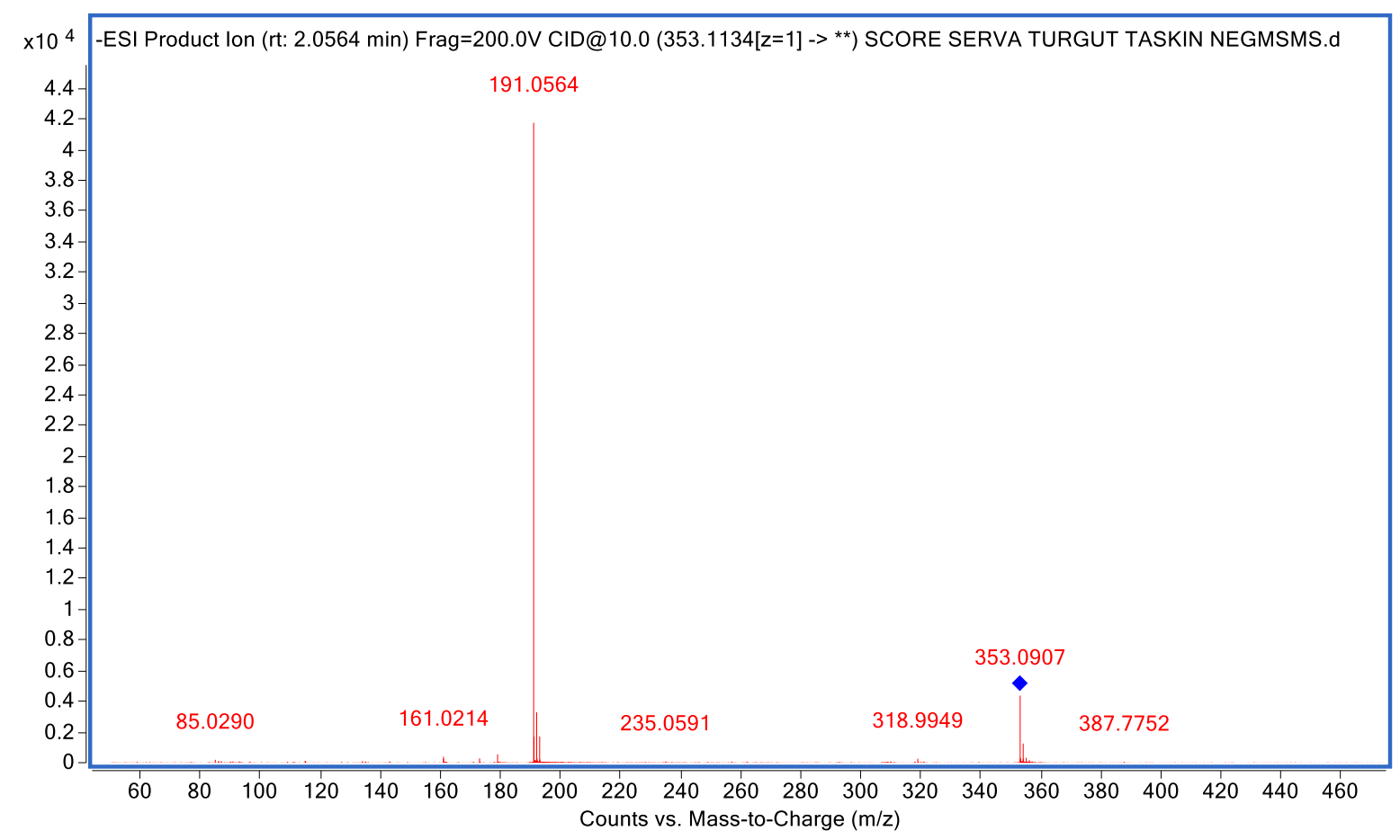


Figure S3. MS/MS spectra and fragmentation patterns of chlorogenic acid dimer in S. veratrifolia.

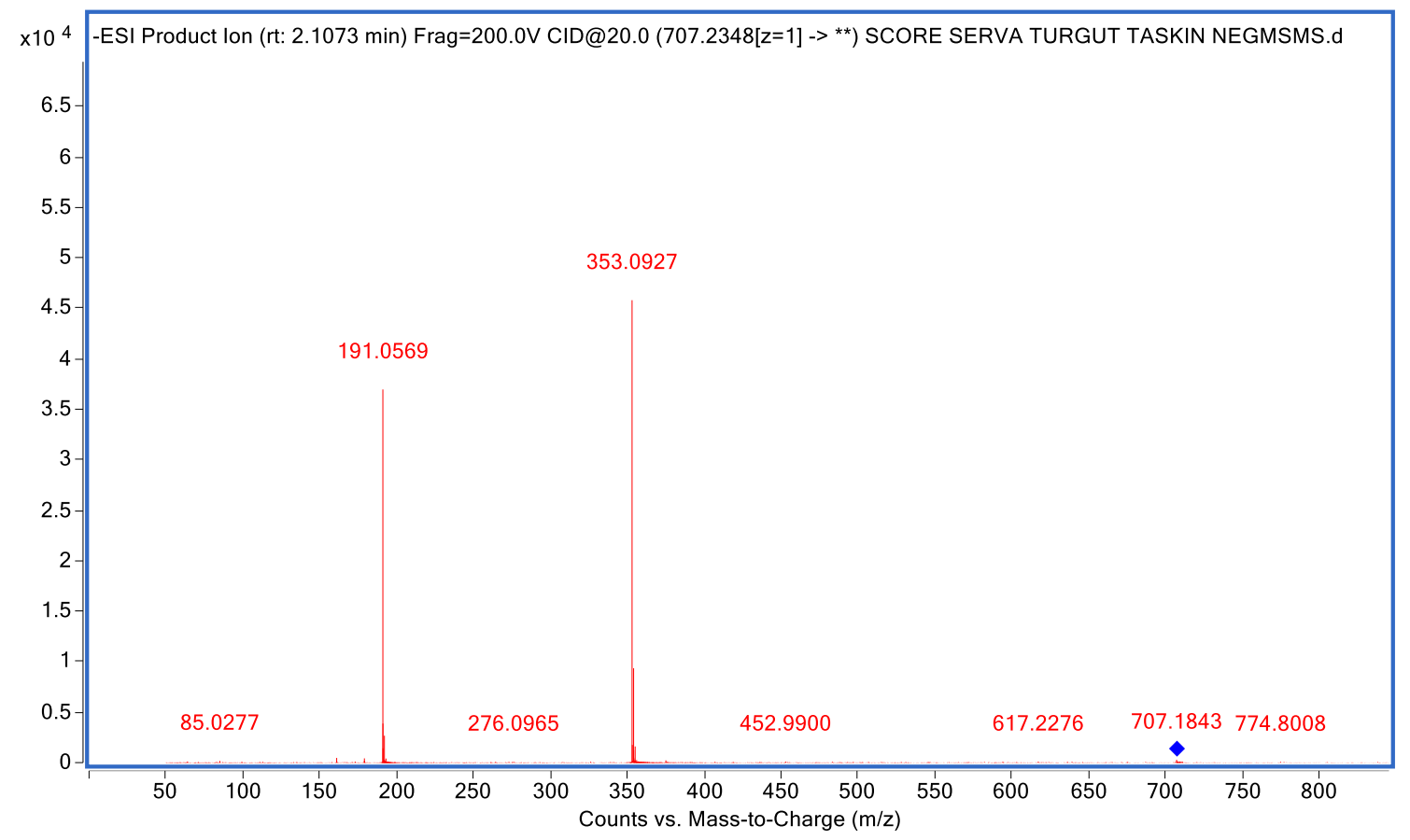

Figure S4. MS/MS spectra and fragmentation patterns of rutin in S. veratrifolia.

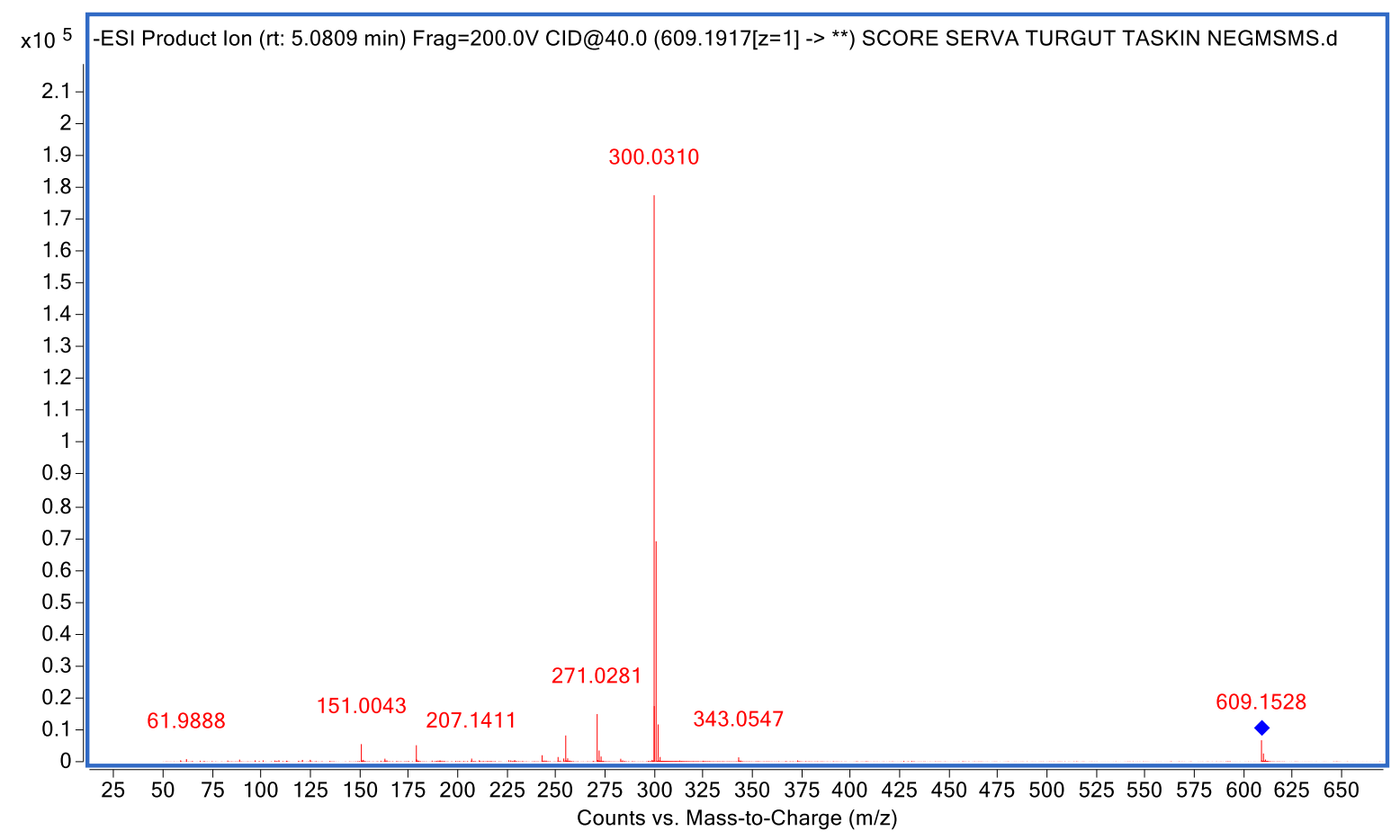


Figure S5. MS/MS spectra and fragmentation patterns of liquiritin in S. veratrifolia.

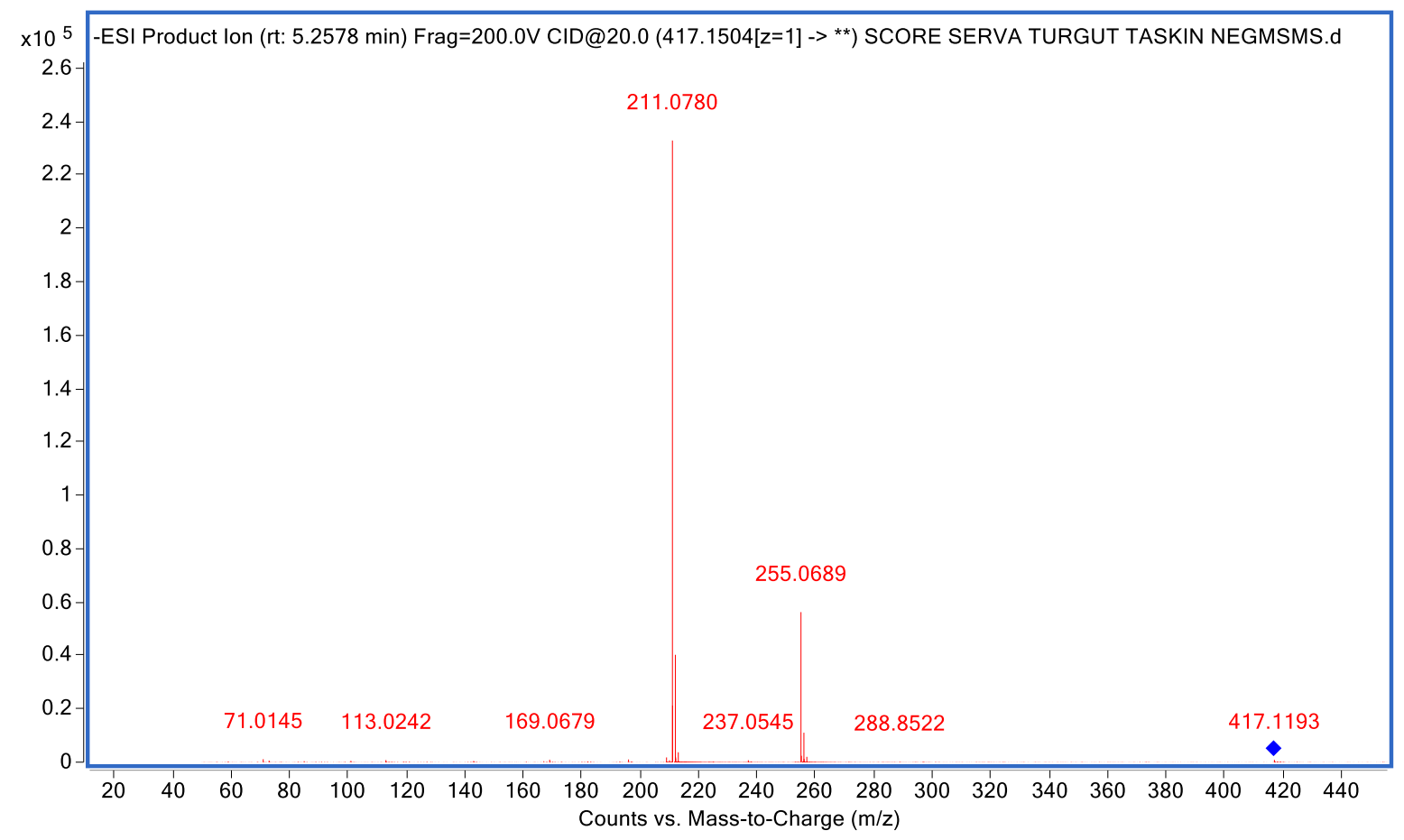

Figure S6. MS/MS spectra and fragmentation patterns of quercetin hexoside in S. veratrifolia.

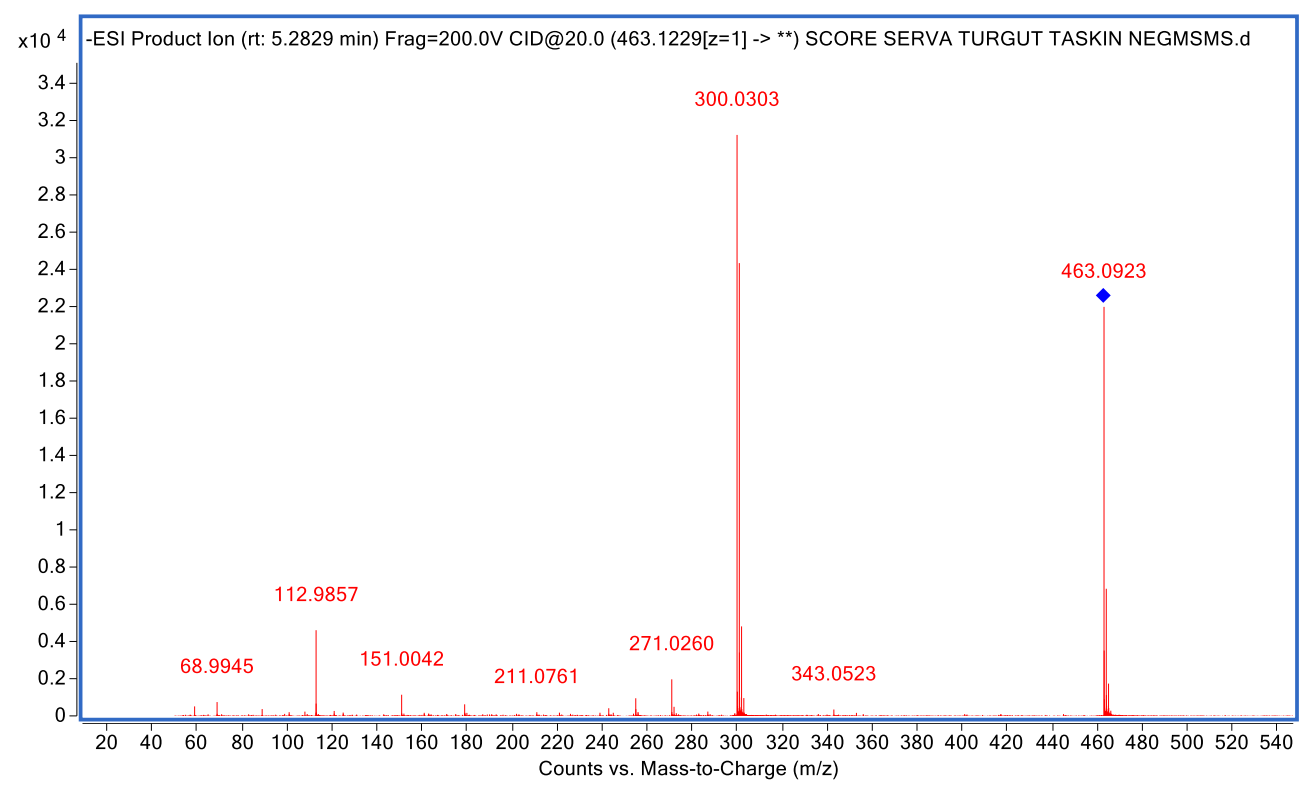


Figure S7. MS/MS spectra and fragmentation patterns of luteolin-7-O-rutinoside in S. veratrifolia.

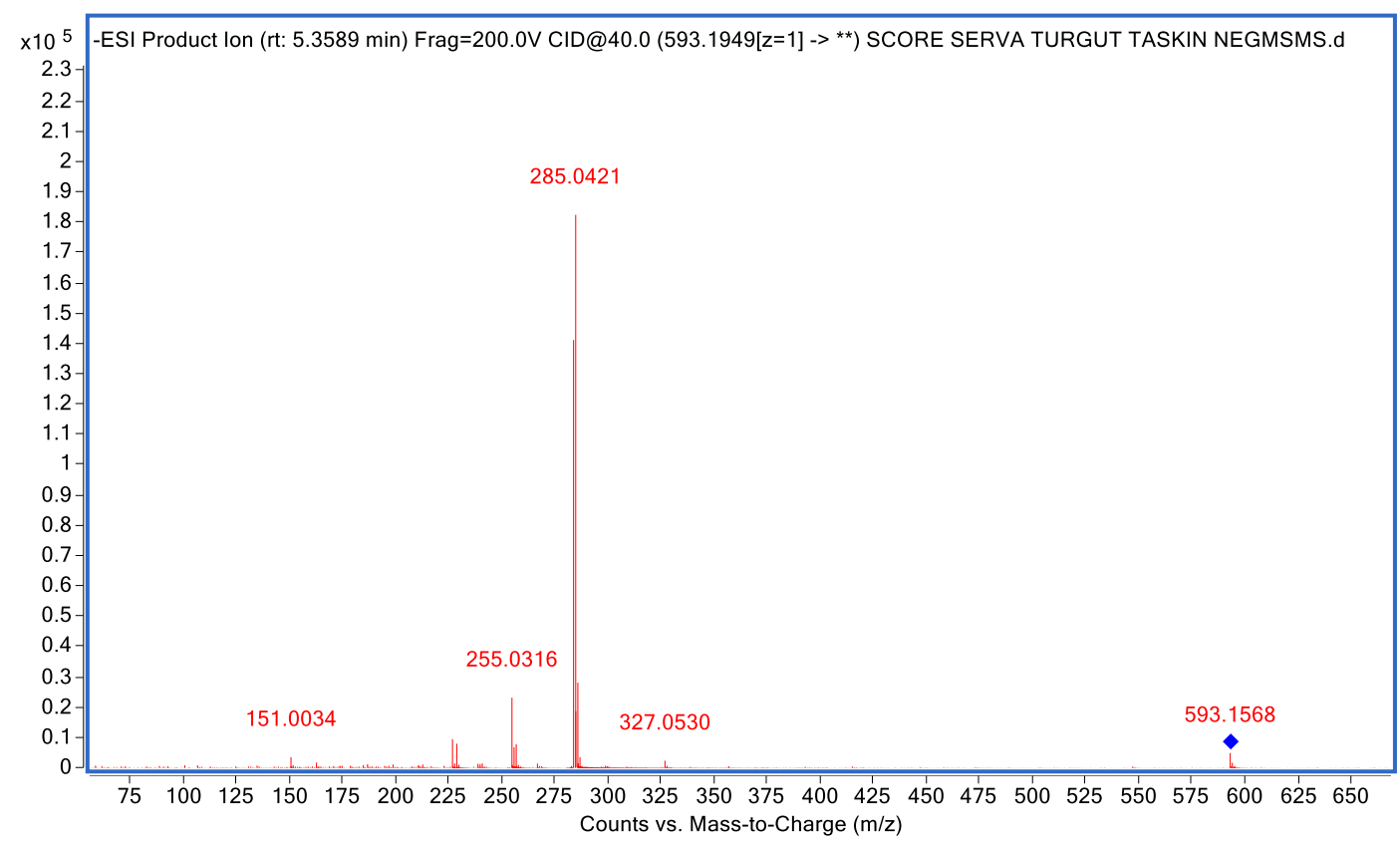

Figure S8. MS/MS spectra and fragmentation patterns of di-O-caffeoylquinic acid in S. veratrifolia.

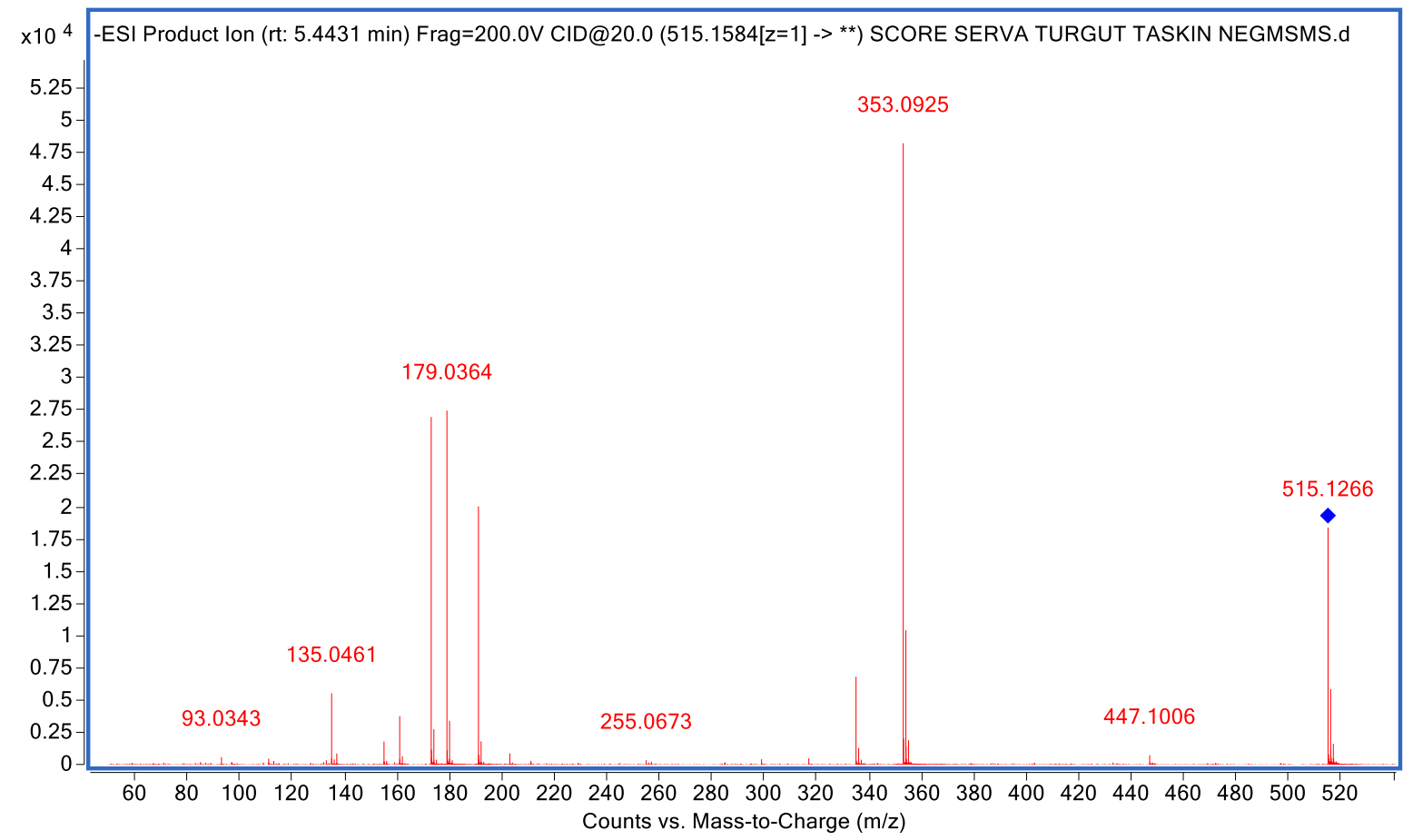


Figure S9. An unknown compounds MS/MS spectra and fragmentation patterns at 5.63 retention time.

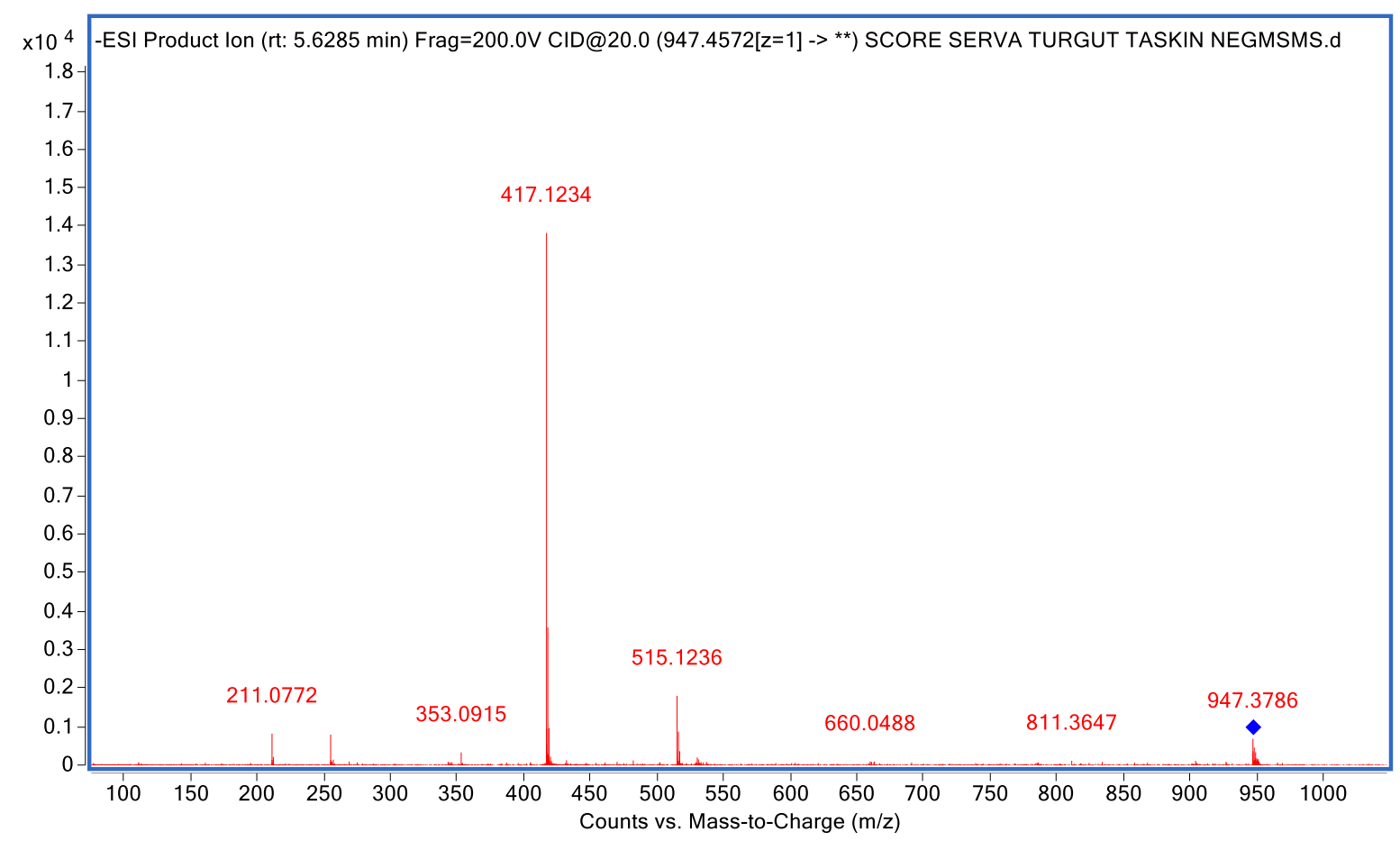

Figure S10. An unknown compounds MS/MS spectra and fragmentation patterns at 5.91 retention time.

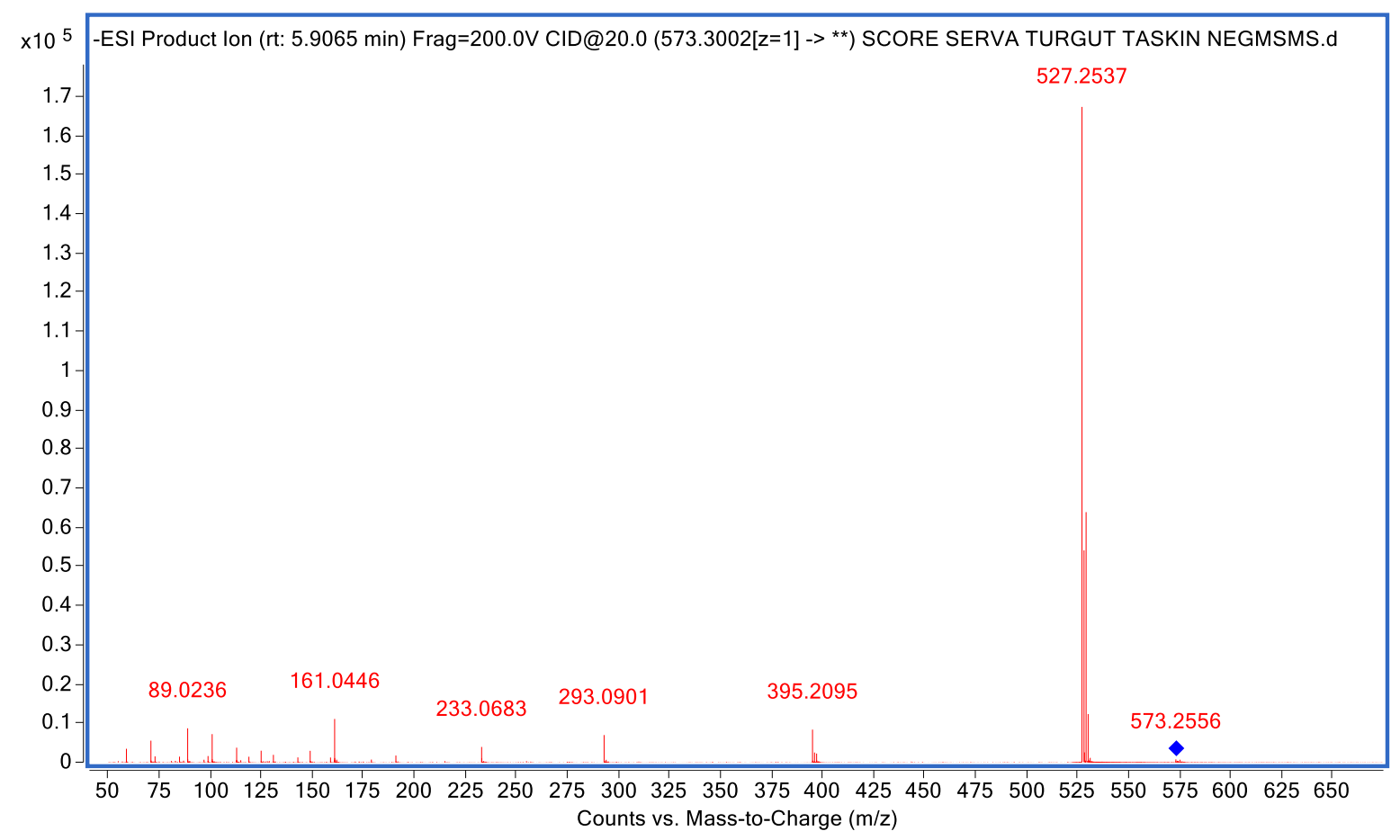


Figure S11. An unknown compounds MS/MS spectra and fragmentation patterns at 6.67 retention time.

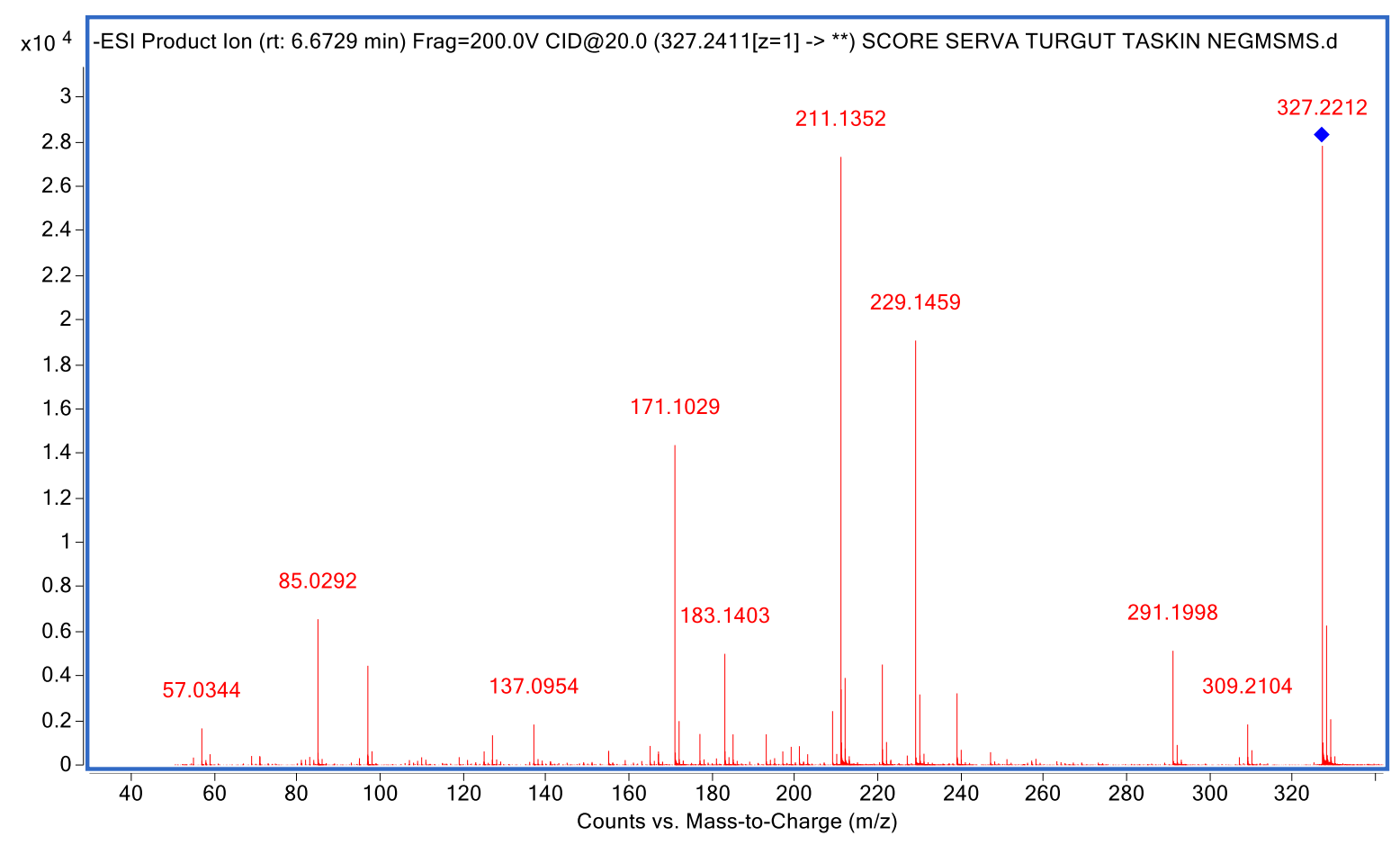

